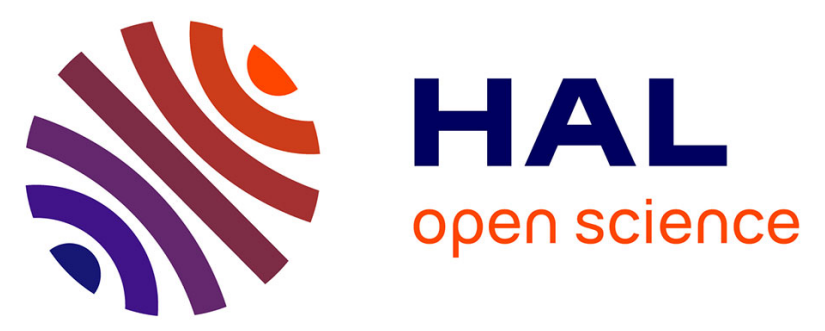

\title{
Spatial segmentation and metabolite annotation involved in sperm maturation in the rat epididymis by MALDI imaging mass spectrometry
}

Mélanie Lagarrigue, Régis Lavigne, Blandine Guével, Andrew Palmer, Karine Rondel, Laetitia Guilot, Jan H. Kobarg, Dennis Trede, Charles Pineau

\section{To cite this version:}

Mélanie Lagarrigue, Régis Lavigne, Blandine Guével, Andrew Palmer, Karine Rondel, et al.. Spatial segmentation and metabolite annotation involved in sperm maturation in the rat epididymis by MALDI imaging mass spectrometry. Journal of Mass Spectrometry, 2020, 55 (12), pp.e4633. 10.1002/jms.4633 . hal-02961181

\section{HAL Id: hal-02961181}

\section{https://hal-univ-rennes1.archives-ouvertes.fr/hal-02961181}

Submitted on 19 Oct 2020

HAL is a multi-disciplinary open access archive for the deposit and dissemination of scientific research documents, whether they are published or not. The documents may come from teaching and research institutions in France or abroad, or from public or private research centers.
L'archive ouverte pluridisciplinaire HAL, est destinée au dépôt et à la diffusion de documents scientifiques de niveau recherche, publiés ou non, émanant des établissements d'enseignement et de recherche français ou étrangers, des laboratoires publics ou privés. 
Lagarrigue Mélanie (Orcid ID: 0000-0003-2146-2776)

\section{Title page}

Title: Spatial segmentation and metabolite annotation involved in sperm maturation in the rat epididymis by MALDI imaging mass spectrometry

Running title: Metabolite annotation in the rat epididymis

Keywords: MALDI imaging mass spectrometry, spatial segmentation, metabolite annotation, epididymis, three-dimensional imaging mass spectrometry.

Authors and affiliations: Mélanie Lagarrigue ${ }^{1,2^{*}}$, Régis Lavigne ${ }^{1,2^{*}}$, Blandine Guével ${ }^{1,2}$, Andrew Palmer ${ }^{3}$, Karine Rondel ${ }^{1,2}$, Laetitia Guilot, Jan H. Kobarg ${ }^{4}$, Dennis Trede ${ }^{4}$, and Charles Pineau ${ }^{1,2 \S}$

${ }^{1}$ Univ Rennes, Inserm, EHESP, Irset (Institut de recherche en santé, environnement et travail) - UMR_S 1085, F-35042 Rennes cedex, France

${ }^{2}$ Protim, Univ Rennes, F-35042 Rennes cedex, France

${ }^{3}$ European Molecular Biology Laboratory, EMBL, Heidelberg, Germany

${ }^{4}$ Bruker Daltonik/SCiLS GmbH, Bremen, Germany

\section{* These authors contributed equally}

Corresponding author : Charles Pineau

263 avenue du Général Leclerc

Bâtiment 24, Etage 4

35042 Rennes Cedex, France

e-mail: charles.pineau@inserm.fr 


\section{Abstract}

Spermatozoa acquire their fertilizing capacity during a complex maturation process that occurs in the epididymis. This process involves a substantial molecular remodeling at the surface of the gamete. Epididymis is divided into three regions (the caput, corpus, and cauda) or into 19 intra-regional segments based on histology. Most studies carried out on epididymal maturation has been performed on sperm samples or tissue extracts. Here, we used MALDI imaging mass spectrometry (IMS) in the positive and negative ion modes combined with spatial segmentation and automated metabolite annotation to study the precise localization of metabolites directly in the rat epididymis. The spatial segmentation revealed that the rat epididymis could be divided into several molecular clusters different from the 19 intraregional segments. The discriminative $\mathrm{m} / \mathrm{z}$ values that contributed the most to each molecular cluster were then annotated and corresponded mainly to phosphatidylcholines, sphingolipids, glycerophosphates, triacylglycerols, plasmalogens, phosphatidylethanolamines and lysophosphatidylcholines. A substantial remodeling of lipid composition during epididymal maturation was observed. It was characterized in particular by an increase in the number of sphingolipids and plasmalogens and a decrease in the proportion of triacylglycerols annotated from caput to cauda. Ion images reveal that molecules belonging to the same family can have very different localizations along the epididymis. For some of them, annotation was confirmed by on-tissue MS/MS experiments. A 3D-model of the epididymis head was reconstructed from 61 sections analyzed with a lateral resolution of $50 \mu \mathrm{m}$ and can be used to obtain information on the localization of a given analyte in the whole volume of the tissue.

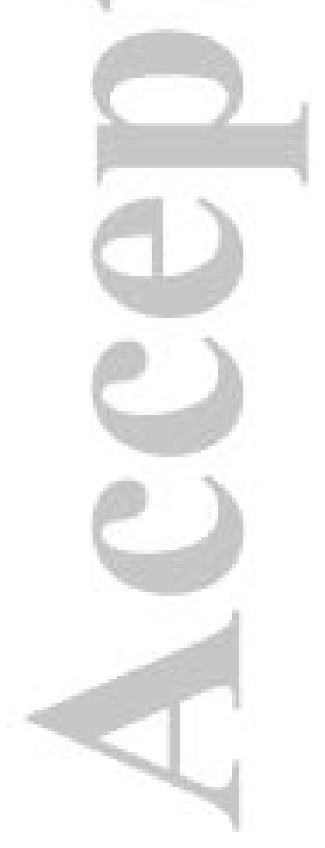




\section{Introduction}

In mammals, spermatozoa released from the testis are morphologically complete but neither motile nor fertile. They acquire their fertilizing capacity during transit through the epididymis, during which a complex maturation process occurs. Such maturation is based on interactions of the spermatozoa with the epididymal micro-environment ${ }^{1,2}$. Notably, a critical remodeling of the proteins and lipids located at the surface of the gamete is observed throughout its transit ${ }^{3,4}$. The epididymis is comprised of a single convoluted tube composed of epithelial cells surrounded by smooth muscle and connective tissue. The complex anatomy of the epididymis is conventionally divided into three major regions: the caput (the proximal region connected to the testis by efferent ductules), corpus, and cauda (the distal region connected to the vas deferens) ${ }^{5,6}$. Epithelial cells of the caput are responsible for water and ion reabsorption and the secretion of proteins that are adsorbed at the surface of spermatozoids. Abundant lipid droplets and vesicles are found in epithelial cells of the corpus and may be involved in modification of the lipid composition of the spermatozoan membrane. At the end of epididymal transit, spermatozoa are stored in the cauda until ejaculation. These three regions can be subdivided into intra-regional segments composed of the epididymal tubule coiled into lobules bounded by connective tissue septa. The number of intra-regional segments depends on the species ${ }^{7,8}$. In the rat, the epididymis can be subdivided into 19 distinct morphological segments based on histology 9 .

The highly regionalized organization of the rat epididymis has been studied at the transcriptomic, proteomic, and metabolomic levels. In 2001, Jervis et al. ${ }^{10}$ used microarray technology to reveal specific expression of several genes in the initial segment, caput, corpus, and cauda. Jelinsky et al. ${ }^{9}$ analyzed gene expression along the 19 micro-dissected segments of the rat epididymis. They found that the expression of approximately 4,000 genes was highly regulated along the various epididymal segments. However, studies carried out at the transcriptomic level are not sufficient to fully understand epididymal maturation, as spermatozoa are mostly transcriptionally and translationally inactive. Moreover, sperm maturation is based on important molecular changes that occur along the epididymal tube, particularly at the level of proteins secreted by the epididymal epithelium or present at the surface of the spermatozoa ${ }^{11,12}$. Yuan et al. thus used a proteomics approach based on 2D-gel electrophoresis and mass spectrometry to identify 28 proteins that are differentially expressed between the caput, corpus, and cauda of rat epididymal tissue ${ }^{13}$. 
The substantial development of metabolomics over the last several years has also opened new perspectives to better understanding the molecular changes involved in epididymal maturation. Recent systematic profiling of metabolites from the epididymal fluid in the caput and cauda of the mouse epididymis have revealed significant differences in metabolite profiles between the caput and cauda lumen fluids ${ }^{14}$. Lipid metabolism is known to play a particularly crucial role in spermatozoan function and maturation ${ }^{15}$. For example, it has been demonstrated that the fluidity of the spermatozoan membrane evolves during epididymal maturation and depends on its lipid composition ${ }^{16}$, of which the modification during epididymal maturation has been further studied in the sperm ${ }^{17,18}$ and epididymosomes ${ }^{19}$ of mice.

Most studies carried out on epididymal maturation have been performed on sperm samples or tissue extracts collected from the caput, corpus, and cauda. This leads to the loss of information on the precise in-situ localization of the studied molecules. MALDI imaging mass spectrometry (IMS) has been applied to various research fields, including reproductive biology, because of its ability to simultaneously localize hundreds of molecules directly on tissue sections without any labeling ${ }^{20}$. In 2003, Chaurand et al. successfully used MALDI IMS and profiling, combined with laser capture microdissection, to study the regionalized expression of proteins along the mouse epididymis ${ }^{21}$. However, although various methodologies have been proposed, the identification of proteins detected by MALDI IMS is still very challenging ${ }^{22,23}$. Unsurprisingly, MALDI IMS of metabolites is rapidly evolving. Indeed, the growing use of high-resolution mass spectrometers combined with the development of algorithms for the annotation of detected metabolites has opened new perspectives for the exploration of metabolomes by MALDI IMS. It was thus recently demonstrated that hundreds of metabolites could be automatically annotated from ion images using a database-driven algorithm ${ }^{24}$. MALDI IMS has also demonstrated its potential in the construction of 3D models from sequential 2D data acquired on successive sections of an entire organ ${ }^{25-29}$. Although mass spectrometers and data analysis are now much faster, the key issues of 3D-IMS are still the huge amount of data generated and time-consuming IMS measurement and data processing, particularly when mass spectrometers with a high mass resolving power are used ${ }^{29}$. Nevertheless, Jones et al. ${ }^{30}$ recently demonstrated the feasibility of $3 \mathrm{D}$ reconstruction of a mouse lung from high resolution Fourier transform-ion cyclotron resonance (FT-ICR) data. 
A large number of metabolic events, particularly lipid metabolism, are suspected to be involved in the epididymal maturation process. Here, we used spatial segmentation and metabolite annotation tools to explore the distribution of metabolites throughout the length of the rat epididymis at a resolution of $50 \mu \mathrm{m}$ by MALDI IMS in the positive and negative ion modes. Information concerning the spatial localization of the metabolites was thus preserved and hundreds of metabolites could be automatically annotated using the METASPACE annotation platform. We also used 3D-MALDI IMS to access and determine the volumetric distribution of metabolites detected in the caput of the rat epididymis.

\section{Experimental}

Chemicals

All chemicals were of the highest purity obtainable. Sodium carboxymethyl cellulose (CMC) was obtained from Thermo Fisher Scientific (Illkirch, France). Methanol, trifluoroacetic acid (TFA) and 9-aminoacridine (9-AA) were purchased from Sigma-Aldrich (Saint-Quentin Fallavier, France). The MALDI matrix 2,5-dihydroxybenzoic acid (DHB) was obtained from Bruker DaltoniK GmbH (Bremen, Germany).

\section{Animals}

90-day-old male Sprague-Dawley rats $(n=2)$ were obtained from Janvier Labs (Le GenestSaint-Isle, France) and reared under ad libitum conditions. Care and handling of all animals complied with EU directive 2010/63/EU on the protection of animals used for scientific purposes. Protocols were approved by the University of Rennes 1 animal experimentation ethics committee.

\section{Sample preparation for MALDI FT-ICR imaging mass spectrometry}

Whole epididymis were excised from animals immediately post-mortem and loosely wrapped in aluminum foil filled with $2 \%$ CMC to preserve the shape of the organs and avoid crushing and distortion. The organs were snap-frozen in cold isopentane and then liquid nitrogen. The frozen tissues were stored at $-80^{\circ} \mathrm{C}$ until use to avoid degradation. The epididymis were cut into two parts named: the "head" (corresponding to the caput and upper corpus) and the "tail" (corresponding to the corpus and cauda) (Figure 1). Tissue sections (20- $\mu \mathrm{m}$ thick) were prepared using a CM3050S cryomicrotome (Leica, Rueil-Malmaison, France), with the chamber chilled to $-22^{\circ} \mathrm{C}$ and the specimen holder to $-15^{\circ} \mathrm{C}$. For $2 \mathrm{D}$ experiments, three 
adjacent sections were collected in the middle of the epididymis head and in the middle of the epididymis tail. Each adjacent section was prepared for MALDI analysis in the positive ion mode, hematoxyline and eosin (H\&E) staining, and MALDI analysis in the negative ion mode, respectively. For 3D experiments, 61 tissue sections were collected every $60 \mu \mathrm{m}$ throughout the epididymis head.

The sections were thaw-mounted onto indium tin oxide (ITO) coated glass slides (Bruker DaltoniK $\mathrm{GmbH}$ ) and immediately desiccated for 5 min under vacuum. Optical images of ITO slides were acquired with a CoolScan V (Nikon). For the positive ion mode, the matrix solution was composed of $50 \mathrm{mg} \cdot \mathrm{mL}^{-1} \mathrm{DHB}$ in $70: 30$ methanol/ $\mathrm{H}_{2} \mathrm{O}$ and $0.1 \%$ TFA. For the negative ion mode, the matrix solution was composed of $10 \mathrm{mg} \cdot \mathrm{mL}^{-1}$ 9-AA in 70:30 ethanol/ $\mathrm{H}_{2} \mathrm{O}$. For $2 \mathrm{D}$ experiments, the DHB and 9-AA solutions were deposited on the slides using a HTX M5 Sprayer device (HTXImaging, Chapel Hill). For 3D experiments, the DHB solution was deposited using an ImagePrep (Bruker $\mathrm{GmbH})$ device. The methods used for matrix deposition are described in Supplementary data 1.

\section{MALDI imaging mass spectrometry}

The prepared slides were mounted on a slide adaptor (Bruker DaltoniK GmbH) and loaded into the MALDI ionization source of a 7 T FT-ICR mass spectrometer SolariX XR equipped with a Paracell (Bruker DaltoniK GmbH) and piloted by ftmsControl software, version 2.1.0 (Bruker DaltoniK GmbH). The instrument was set to a resolving power of 130,000 at $\mathrm{m} / \mathrm{z}=$ 400 in the positive or negative ion mode. The Smartbeam-II laser focus was set to 'small' $(20-30 \mu \mathrm{m})$. For each pixel, a spectrum was accumulated from 100 laser shots. The laser was run at $1,000 \mathrm{~Hz}$ and the ions accumulated externally (hexapole) before being transferred into the ICR cell for a single scan. Every spectrum was internally calibrated by multipoint correction in positive $\left(\left[\mathrm{C}_{14} \mathrm{H}_{9} \mathrm{O}_{6}+\mathrm{H}\right]^{+} \mathrm{m} / z\right.$ 273.039364, $\left[\mathrm{C}_{21} \mathrm{H}_{13} \mathrm{O}_{9}+\mathrm{H}\right]^{+} \mathrm{m} / z$ 409.055408, $\left[\mathrm{C}_{34} \mathrm{H}_{32} \mathrm{FeN}_{4} \mathrm{O}_{4}+\mathrm{H}\right]^{+} m / z$ 616.176804, $\left[\mathrm{C}_{40} \mathrm{H}_{80} \mathrm{NO}_{8} \mathrm{P}+\mathrm{H}\right]^{+} \mathrm{m} / z$ 734.569432, $\left[\mathrm{C}_{42} \mathrm{H}_{82} \mathrm{NO}{ }_{8} \mathrm{P}+\mathrm{H}\right]^{+}$ $m / z \quad 760.585082, \quad\left[\mathrm{C}_{42} \mathrm{H}_{82} \mathrm{NO}{ }_{8} \mathrm{P}+\mathrm{Na}\right]^{+} \quad m / z \quad 782.567026, \quad$ and $\left[\mathrm{C}_{42} \mathrm{H}_{82} \mathrm{NO}{ }_{8} \mathrm{P}+\mathrm{K}\right]^{+} \mathrm{m} / z$ $798.540963)^{24}$ and in negative $\left(\left[\mathrm{C}_{13} \mathrm{H}_{10} \mathrm{~N}_{2}-\mathrm{H}\right]^{-} \mathrm{m} / z\right.$ 193.076025, $\left[\mathrm{C}_{21} \mathrm{H}_{41} \mathrm{O}_{6} \mathrm{P}-\mathrm{H}\right]^{-} \mathrm{m} / z$ 419.255702, $\left[\mathrm{C}_{27} \mathrm{H}_{53} \mathrm{O}_{12} \mathrm{P}-\mathrm{H}\right]^{-} \mathrm{m} / z$ 599.319091, and $\left[\mathrm{C}_{41} \mathrm{H}_{80} \mathrm{O}_{12} \mathrm{~S}-\mathrm{H}\right]^{-} \mathrm{m} / z$ 885.548756) ion modes. Data were acquired in the $\mathrm{m} / \mathrm{z}, 100-1200$ mass range followed by single-zero filling and sin-apodization. Image analysis and data visualization were performed with FlexImaging 5.0 software (Bruker Daltonik $\mathrm{GmbH})$. The $\mathrm{x}-\mathrm{y}$ raster width, defining the lateral resolution of ion images, was set to $50 \mu \mathrm{m}$. On-line feature reduction was performed by ftmsControl to 
return only peak centroids and intensities and generate a peak list of the data in SQLite format. On-tissue collision-induced dissociation (CID) experiments were performed with an isolation width of $2 \mathrm{~m} / \mathrm{z}$ around the precursor ion of interest and a Q1 CID energy between 10 and $40 \mathrm{~V}$, depending on the selected precursor ion.

\section{Spatial segmentation}

After MALDI acquisition, the .mis files generated by FlexImaging from head and tail sections were imported into the 2016b version of SCiLS Lab software (SCiLS, Bremen, Germany) using the SQLite peak list data. Then, the spatial segmentation process, available in SCiLS Lab and already described for 2D MALDI IMS ${ }^{31,32}$, was used with the following parameters: RMS normalization ${ }^{33}$, work on all individual spectra, weak denoising, and a minimal interval width of $3 \mathrm{ppm}$. The bisecting k-means algorithm, consisting of a hierarchical top-down clustering method that iteratively divides a set of spectra into two sets that are maximally different, was used as the clustering method for faster processing ${ }^{31,34}$. Briefly, after peak picking, edge-preserving median filter denoising was applied to the $m / z$ images of detected peaks. The reduced and processed spectra were thus clustered by their spectral similarity. The spatial segmentation results are presented as spatial segmentation maps and corresponding hierarchical dendrograms composed of clusters, with pseudo-colors assigned to pixels (or individual spectra) belonging to each cluster.

\section{Determination of discriminative $\mathrm{m} / \mathrm{z}$ values}

SCILS lab was used to determine $m / z$ values discriminating each of the clusters obtained in the positive and negative ion modes from the spatial segmentation maps ${ }^{32,35}$. First, the pixels (or spectra) constituting each of the clusters were defined as regions by SCILS lab. Then, a univariate receiver operating characteristic (ROC) curve analysis was performed for each region by defining this region as the first group and all the other regions as the second group. All imported peaks from all individual spectra with an interval width of $3 \mathrm{ppm}$ were used. Peaks $(\mathrm{m} / \mathrm{z}$ values) providing an area under the curve (AUC) $>0.80$ after the ROC curve analysis were considered to be significantly discriminative ${ }^{35}$. It is important to note that ROC curve analysis measures the discrimination quality of $\mathrm{m} / \mathrm{z}$ ratios. A given discriminative $\mathrm{m} / \mathrm{z}$ value can thus be found in several clusters with different discrimination qualities. 


\section{Metabolite annotation}

Analyzed sections were exported in the imzML format using SCiLS Lab 2016b and submitted to the METASPACE molecular annotation engine (http://annotate.metaspace2020.eu/about, ${ }^{24}$ ). Metabolite annotations were assigned from four different databases (HMDB-v4, ChEBI-2018-01, LipidMaps-2017-12-12, and SwissLipids-2018-02-02) on the basis of accurate mass and matched isotope distributions measured with a high-resolving mass spectrometer, leading to the calculation of a metabolite signal match (MSM) score. An MSM score cut-off was applied to reach a false discovery rate (FDR) of $<10 \%$. The correlation between the theoretical $\mathrm{m} / \mathrm{z}$ of annotations provided by Metapace and experimental $\mathrm{m} / z$ of discriminant ions detected by SCILS was performed on the basis of a $\Delta m / z<3 \mathrm{ppm}$. When a $\Delta m / z<3 \mathrm{ppm}$ was observed between two annotations proposed by Metaspace, manual curation was performed by verifying the co-localization of the salt adducts $\left(\mathrm{H}^{+}, \mathrm{Na}^{+}\right.$, and $\left.\mathrm{K}^{+}\right)$.

\section{$3 D$ model construction}

The 3D model was reconstructed with images acquired from the 61 sections collected from an epididymis head with a lateral resolution of $50 \mu \mathrm{m}$. This 3D model was generated from 990,369 spectra, representing approximately 550 hours of MALDI FT-ICR acquisition and 778 GB of raw data. The $2018 \mathrm{~b}$ version of SCiLS Lab 3D software was used to construct and visualize this 3D MALDI IMS model. Each individual imaging analysis (.mis file) was combined in sequential order into a single SCiLS experiment. The 3D volume was reconstructed by rigid co-registration of individual optical images acquired from each tissue section. All optical images were then manually stacked and aligned based on the histological knowledge of the epididymal tubule evolution inside each part of the organ. We used the "image differentiation" option to assess the quality of the alignment between two consecutive sections, as previously described ${ }^{36}$. Voxels were defined by the lateral resolution and the distance between the sections $(50 \mu \mathrm{m} \times 50 \mu \mathrm{m} \times 60 \mu \mathrm{m})$. The $3 \mathrm{D}$ model was calculated using a classic computer equipped with 32 gigabytes of RAM and a dual processor. The processing took almost two weeks and generated a 3D model of approximately 200 GB.

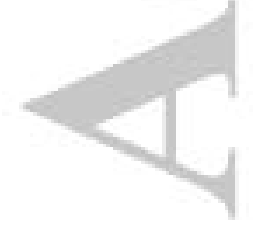




\section{Results and Discussion}

Different segmentation of the rat epididymis is deduced at the histological and molecular levels

Sections collected in the middle of the epididymis head and the epididymis tail were considered to be representative of rat epididymis morphology, typically divided into 19 distinct intra-regional segments, as described by Jelinsky et al. ${ }^{9}$. These segments, corresponding to lobules bounded by connective tissue septa, were identified in the optical image of these sections (Figure 1A). Spatial segmentation was then performed on MALDI IMS data obtained from the epididymis sections analyzed in the positive (Figure 1B) and in the negative (Figure 1C) ion modes. This unsupervised clustering approach allows the representation of a dataset in different clusters containing similar molecular features without any prior histological knowledge ${ }^{32}$. This enabled us to consider the epididymis from an alternative point of view, based only on molecular and spatial information. The generated spatial segmentation maps were then explored with different numbers of clusters. We limited the exploration of the spatial segmentation map until a number of clusters representing approximately $1 \%$ of the total number of pixels was reached to simplify visualization of the results. The segmentation maps obtained in the positive (Figure 1B) and negative (Figure 1C) ion modes were composed of 24 and 22 clusters, respectively. Clusters of the spatial segmentation maps obtained from molecular features based on metabolites (Figure 1B-C) were then compared to the 19 intra-regional segments defined from histological observation (Figure 1A). This comparison revealed that intra-regional segments determined by histology to actually be composed of several molecular clusters of the spatial segmentation maps (Table 1).

In the positive ion mode (Figure 1B), clusters 01 to 08 corresponded to the upper part of the caput, comprised of histological segments 1 to 7 , whereas clusters 09 to 15 corresponded to the lower part of the caput and the upper part of the corpus (segments 8 to 12). Clusters 16 to 18 could be attributed to the corpus and the beginning of the cauda (segments 13 to 16) and clusters 19 to 21 to segments 17 to 19 of the cauda. We also noticed concentric distributions of clusters 20 to 24 in segments 18 and 19 (Figure 1E) that could be attributed to different histological structures of the cauda discerned on the optical image. Cluster 23 was thus observed all around the epididymal duct and could be attributed to connective tissue. Clusters 20 and 22 were finely located at the edge of the epididymal duct and could correspond to smooth muscle and epithelium, respectively. This histological annotation was obtained from 
an adjacent section stained with $H \& E$ (Figure 1D). As smooth muscle and epithelium are very thin structures, a better confidence in this annotation could have been obtained by staining the epididymis sections analysed by MALDI IMS with H\&E after matrix removal ${ }^{37}$. However, probably due to the absence of dehydration step in the preparation of tissue sections for MALDI IMS of metabolites, the integrity of our epididymis sections was not sufficiently preserved (particularly in the epithelium area) to be used for the confirmation of our histological annotation. Nevertheless, the decrease in the thickness of cluster 22 across the cauda is consistent with the fact that the epididymal epithelium is known to be shorter in the cauda than the caput or corpus ${ }^{38}$, thus reinforcing our confidence this attribution. Interestingly, sperm stored in segments 17, 18 and 19 was associated with the distinct clusters 19, 21 and 24. Experiments performed on another animal provided very similar results, suggesting that the reproducibility of the spatial segmentation map is good (Supplementary Figure 1).

The clusters calculated from the spatial segmentation in negative ion mode (Figure 1C) were quite different from those obtained in positive ion mode (Figure 1B). Contrary to the positive ion mode, no clear differentiation of connective tissue and smooth muscle was observed in segments 18 and 19 (Figure 1F). Interestingly, segments 4, 5 and 7 were associated to the same clusters in the positive ion mode but also in the negative ion mode (Table 1), suggesting a strong molecular similarity between these segments. The same observation can be done for segments 10 and 11 but also for segments 13 to 16 (Table 1 ).

Annotation of $\mathrm{m} / \mathrm{z}$ values discriminating each molecular cluster confirms the substantial evolution of lipid composition from the caput to cauda

We performed statistical ROC curve analyses to assess the discriminative quality of $\mathrm{m} / \mathrm{z}$ values detected in each cluster of the spatial segmentation map. ROC curves are constructed by calculating the specificity and sensitivity of each $\mathrm{m} / \mathrm{z}$ ratio when various intensity thresholds are applied. The discriminative quality of each $\mathrm{m} / \mathrm{z}$ value is thus reflected by the area under the ROC curve (AUC): an AUC of 0.5 reflects the total absence of discrimination whereas an AUC of 1 corresponds to perfect discrimination. For each molecular cluster, $\mathrm{m} / \mathrm{z}$ values presenting an AUC $>0.80$ were considered to be significantly discriminative. All AUC $>0.8$ for which an annotation was obtained are reported in Supplementary Table 1. 
We first separately compared annotations corresponding to discriminative $m / z$ values in the head (segments 1 to 12 ) and tail (segments 13 to 19 ) sections. When a $\mathrm{m} / \mathrm{z}$, value was discriminative in several clusters of the same main region (head or tail), only those leading to the AUC with the value closest to 1 in this region are reported (Supplementary Table 2). When several salt adducts $\left(\mathrm{H}^{+},-\mathrm{H}^{-}, \mathrm{Na}^{+}, \mathrm{Cl}^{-}\right.$, or $\left.\mathrm{K}^{+}\right)$were observed for a given molecular formula, the distribution of the salt adducts was inspected manually in Metaspace. Indeed, artefacts induced by variation in salts concentration in the different regions of the tissue cannot be excluded. Among 218 molecular formula reported in Supplementary Table 1, only 7 presented some differences in the localization of the salt adducts. The different adducts $\left(\mathrm{H}^{+}\right.$, $-\mathrm{H}^{-}, \mathrm{Na}^{+}, \mathrm{Cl}^{-}$, or $\mathrm{K}^{+}$) of a given molecular species were thus considered to be duplicates and only the adduct providing the AUC with the value closest to 1 was reported. Donut charts of the discriminative $\mathrm{m} / \mathrm{z}$ annotated in the head (Figure 2A) and tail (and 2B) of the epididymis show that the obtained annotations correspond mainly to lipids. This is not surprising, because the sample preparation, selected matrix solutions, and mass range used for the MALDI IMS experiments were highly favourable for lipid detection. Experiments were carried out in the positive and negative ion modes in order to detect complementary molecular classes in the rat epididymis. However, as reported in previous studies ${ }^{17,39}$, we observed that spectra obtained in the negative ion mode were largely dominated by a seminolipid (SL(16:0/16:0) $[\mathrm{M}-\mathrm{H}]^{-} \mathrm{m} / z$ 795.5318) but also by glycerophosphoinositol $\left(\left[\mathrm{C}_{9} \mathrm{H}_{19} \mathrm{O}_{11} \mathrm{P}-\mathrm{H}\right]^{-} \mathrm{m} / \mathrm{z}, 333.0577\right)$. These dominant ions were not annotated by Metaspace because they are not referenced in the four queried databases. They were thus identified thanks to MS/MS experiments performed directly on the tissue section (Supplementary Figure 3). Based on accurate mass, two other unannotated $\mathrm{m} / \mathrm{z}$ could be attributed to seminolipids (Supplementary Table 1). However, as their intensity was too low to achieve interpretable MS/MS spectra, these annotations should be considered with caution. Despite the wide dynamic range of the FT-ICR, the large predominance of $\mathrm{m} / z 795.5318$ and 333.0577 led unfortunately to a much lower number of annotations in the negative ion mode (68) compared to the positive mode (415). However, some species such as lysophosphatidylethanolamines (LysoPEs), phosphatidylinositols (PIs) and seminolipids (SLs) were only detected in the negative ion mode.

Half the discriminative $\mathrm{m} / \mathrm{z}$ values annotated in the epididymis head corresponded to phosphatidylcholines (PCs), sphingolipids, glycerophosphates (PAs), triacylglycerols (TGs), and plasmalogens in similar proportions (9 to 12\%). Phosphatidylethanolamines (PEs), 
lysophosphatidylcholines (LysoPCs), phosphatidylserines (PSs), phosphatidylglycerols (PGs), diacylglycerols (DGs), and LysoPEs represented each 4 to $6 \%$ of annotated discriminative $\mathrm{m} / \mathrm{z}$ (Figure 2A). Other lipids (PIs, SLs, fatty acyls, prenol lipids, steroids and derivatives, sterol lipids, glycerophosphoglycerophosphoglycerols, and lipid-like molecules) and other organic compounds (flavonoids, dipeptides, phenylpropanoids, and nucleosides) corresponded to $16 \%$ and $6 \%$ of the annotations, respectively. In the epididymis tail (Figure 2B), the proportion of sphingolipids (19\%), plasmalogens (17\%) and other organic compounds (nucleosides, flavonoids, organoheterocyclic compounds, carbohydrates, phenylpropanoids, and heme, 17\%) strongly increased and was associated to a smaller proportion of discriminative TGs, PCs, PAs, DGs and PEs (1 to 8\%) (Figure 2B). Experiments performed on another animal provided the same trends for PCs, sphingolipids, PAs, TGs, plasmalogens, LysoPCs, and other organic compounds representing more than $75 \%$ of annotations, suggesting a good reproducibility of our results (Supplementary Figure 2).

We then calculated the distribution of annotations obtained for discriminative $\mathrm{m} / \mathrm{z}$ ratios for each molecular cluster individually to refine the analysis. When different adducts were detected for the same molecular species in a given cluster, only the adduct providing AUC with the value closest to 1 is reported (Supplementary Table 3). The number of discriminative $\mathrm{m} / \mathrm{z}$ annotated in the negative ion mode (158) was significantly lower than that obtained in the positive ion mode (708). The distribution of annotated discriminative $\mathrm{m} / \mathrm{z}$ presented in Figure $2 \mathrm{C}$ thus corresponds to clusters obtained in the positive ion mode. Clusters 01 to 09 of the caput were associated to an important proportion of PCs. A specific apparition of TGs was observed in clusters 09 (caput) and 15 (corpus). The number of discriminative $\mathrm{m} / \mathrm{z}$ was globally lower in the corpus (clusters 10 to 18), suggesting that fewer specific molecular events occur in this region of the epididymis. In contrast, the cauda (clusters 19 to 24) was marked by an increase in the number of discriminative $\mathrm{m} / \mathrm{z}$ and a diversification of the detected molecular classes compared to the caput and corpus. Indeed, sphingolipids, plasmalogens, and other organic compounds (mainly nucleosides and analogues) strongly increased in these clusters.

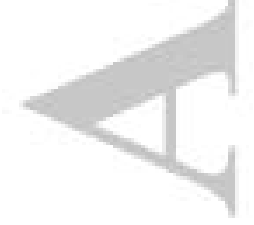




\section{MALDI IMS reveals the in-situ localization of discriminative $\mathrm{m} / \mathrm{z}$ ratios}

Spatial segmentation allowed us to observe the evolution of the lipid composition in the rat epididymis by determining the molecular clusters. The in-situ localization of a number of discriminative $m / z$ ratios was then studied more specifically. Ion images corresponding to $\mathrm{PC}(32: 0) \quad[\mathrm{M}+\mathrm{K}]^{+} \mathrm{m} / z$ 772.525, $\mathrm{PC}(34: 1) \quad[\mathrm{M}+\mathrm{K}]^{+} \mathrm{m} / z$ 798.541, $\mathrm{PC}(36: 2) \quad[\mathrm{M}+\mathrm{H}]^{+} \mathrm{m} / \mathrm{z}$ 786.600, and $\mathrm{PC}(38: 5)[\mathrm{M}+\mathrm{Na}]^{+} \mathrm{m} / z 830.569$ are shown in Figure 3A. These putative molecular annotations provided by METASPACE are based on accurate mass and matched isotope distributions. Only MS/MS experiments can provide characteristic ions for the validation of these annotations. MS/MS experiments can be performed either directly on tissue sections with the same instrument or on tissue homogenates by liquid chromatography (LC) coupled to electrospray ionization tandem mass spectrometry (ESI-MS/MS). The LCMS/MS approach results in a higher number of metabolite identifications, due to the addition of a separation step, but is based on an ionization technique different from that used in MALDI IMS. This can lead to difficulties in correlating LC-ESI-MS/MS and MALDI IMS data because it is known that molecular species can have very different behaviors in ESI and in MALDI. Here, on-tissue CID experiments were performed directly on tissue sections because it did not require a supplementary step of metabolite extraction and was based on the same instrumentation. Moreover, MS/MS information could be specifically obtained from the same tissue region in which the compound of interest was originally detected. The resulting MS/MS spectra are shown in Supplementary Figure 3. PC $[\mathrm{M}+\mathrm{H}]^{+}$ions were identified by the characteristic fragment ion observed at $\mathrm{m} / \mathrm{z}$ 184, corresponding to the protonated phosphocholine head, whereas $\mathrm{PC}[\mathrm{M}+\mathrm{Na}]^{+}$or $[\mathrm{M}+\mathrm{K}]^{+}$ions led to the characteristic neutral losses of 59 (trimethylamine) and $183 \mathrm{Da}$ (neutral phosphocholine head) ${ }^{40}$. On-tissue MS/MS experiments globally facilitated the correlation between MS/MS and MALDI IMS data but were limited, however, to the identification of relatively abundant species and could not resolve fatty-acid chains. Nevertheless, our MS/MS spectra were consistent with annotations provided by METASPACE, thus strengthening our confidence in the global annotation.

Although they belong to the same lipid family, $\mathrm{PC}(32: 0)[\mathrm{M}+\mathrm{K}]^{+}, \mathrm{PC}(34: 1)[\mathrm{M}+\mathrm{K}]^{+}$, $\mathrm{PC}(36: 2)[\mathrm{M}+\mathrm{H}]^{+}$, and $\mathrm{PC}(38: 5)[\mathrm{M}+\mathrm{Na}]^{+}$showed very different localization along the epididymis (Figure 3A). PC(32:0) $[\mathrm{M}+\mathrm{K}]^{+}$was almost only detected in the connective tissue of segments 18 and 19 of the cauda whereas $\mathrm{PC}(34: 1)[\mathrm{M}+\mathrm{K}]^{+}, \mathrm{PC}(36: 2)[\mathrm{M}+\mathrm{H}]^{+}$, and $\mathrm{PC}(38: 5)[\mathrm{M}+\mathrm{Na}]^{+}$were also detected in the caput and/or corpus. $\mathrm{PC}(34: 1)[\mathrm{M}+\mathrm{K}]^{+}$was 
abundantly detected in the caput (segments 6, 8 and 9) and corpus (segments 10 to 12). $\mathrm{PC}(36: 2)[\mathrm{M}+\mathrm{H}]^{+}$and $\mathrm{PC}(38: 5)[\mathrm{M}+\mathrm{Na}]^{+}$were both moderately abundant in segments 1 to 3 , and 8 but showed opposite trends in the other segments: the abundance of $\mathrm{PC}(36: 2)[\mathrm{M}+\mathrm{H}]^{+}$ was low in segments 4 to 7 and very high in segments 9 to 16 , whereas the intensity of $\mathrm{PC}(38: 5)[\mathrm{M}+\mathrm{Na}]^{+}$was strong in segments 4 to 7 but weak in segments 9 to 16 . All PCs presented in Figure 3A were detected in segments 18 and 19 of the cauda but with a different localization: $\mathrm{PC}(32: 0)[\mathrm{M}+\mathrm{K}]^{+}$and $\mathrm{PC}(34: 1)[\mathrm{M}+\mathrm{K}]^{+}$were both abundant in the connective tissue, whereas $\mathrm{PC}(36: 2)[\mathrm{M}+\mathrm{H}]^{+}$was detected in the smooth muscle and $\mathrm{PC}(38: 5)[\mathrm{M}+\mathrm{Na}]^{+}$ was weakly detected in the sperm stored inside the epididymal tube. On-tissue MS/MS experiments confirmed the nature of the PCs but could not provide information on the composition of the fatty-acid chains. However, $\mathrm{PC}(34: 1)[\mathrm{M}+\mathrm{K}]^{+} \mathrm{m} / \mathrm{z} 798.541$ could be attributed to $\mathrm{PC}(16: 0 / 18: 1)[\mathrm{M}+\mathrm{K}]^{+}$and $\mathrm{PC}(36: 2)[\mathrm{M}+\mathrm{H}]^{+} \mathrm{m} / z 786.600$ to $\mathrm{PC}(18: 0 / 18: 2)$ by comparing our annotations with identifications obtained by electrospray ionization (ESI)MS/MS in the study carried out by Sato et al. on epididymal sperm in mice ${ }^{18}$.

LysoPCs can be generated either from PCs by the action of the large family of phospholipases A2, which hydrolyze the sn-2 position of PC or reactive oxygen species (ROS) generated during inflammation ${ }^{41}$. They are known to play a crucial role in spermatozoa function and can be considered to be markers of sperm quality ${ }^{41}$. Ion images of LysoPC(18:0) $[\mathrm{M}+\mathrm{Na}]^{+} m / z$ 546.353, LysoPC(18:2) $[\mathrm{M}+\mathrm{H}]^{+} m / z$ 520.339, LysoPC(20:4) $[\mathrm{M}+\mathrm{K}]^{+} m / z$ 582.296, and $\operatorname{LysoPC}(22: 4)[\mathrm{M}+\mathrm{H}]^{+} m / z, 572.371$ are shown in Figure 3B. Interpretable on-tissue MS/MS spectra were very difficult to obtain for LysoPCs because of their very low intensities. Nevertheless, on-tissue CID performed on $\operatorname{LysoPC}(20: 4)[M+K]^{+}$ $\mathrm{m} / \mathrm{z} 582.296$ led to a MS/MS spectrum of poor quality but showing a loss of $59 \mathrm{Da}$, consistent with our annotation (Supplementary Figure 3). LysoPCs shown in Figure 3B present very different distributions. LysoPC(18:0) $[\mathrm{M}+\mathrm{Na}]^{+}$and $\operatorname{LysoPC}(22: 4)[\mathrm{M}+\mathrm{H}]^{+}$were both detected in the sperm but with opposite trends: LysoPC(18:0) $[\mathrm{M}+\mathrm{Na}]^{+}$intensity decreased from segment 4 to 15 whereas $\operatorname{LysoPC}(22: 4)[\mathrm{M}+\mathrm{H}]^{+}$intensity increased from segments 9 to 19. LysoPC(18:2) $[\mathrm{M}+\mathrm{H}]^{+}$and LysoPC(20:4) $[\mathrm{M}+\mathrm{K}]^{+}$were detected in different segments of the caput and corpus but also in the last segments of the cauda. These results are quite different to that obtained in lipid extracts of mouse caput and cauda spermatozoa by Pyttel et al. ${ }^{17}$. Indeed, they observed an enhanced content of lysolipids, including LysoPC(18:0), LysoPC(18:2) and LysoPC(20:4) in the cauda spermatozoa while our ion images suggest a more pronounced localization of these lipids in the caput and corpus tissue. 
Spatial segmentation also revealed marked differences in sphingolipids, plasmalogens and TGs composition between the caput and cauda. Molecular images of several sphingolipids $\left(\mathrm{SM}(\mathrm{d} 34: 1)[\mathrm{M}+\mathrm{K}]^{+} \mathrm{m} / z, 741.531, \mathrm{SM}(\mathrm{d} 42: 0)[\mathrm{M}+\mathrm{H}]^{+} \mathrm{m} / z\right.$ 675.544, $\mathrm{SM}(\mathrm{d} 42: 2)[\mathrm{M}+\mathrm{H}]^{+} \mathrm{m} / z$ 813.684, and $\mathrm{SM}(\mathrm{d} 36: 1)[\mathrm{M}+\mathrm{Na}]^{+} \mathrm{m} / \mathrm{z}$ 753.588), plasmalogens $\left(\mathrm{PC}(\mathrm{P}-36: 1)[\mathrm{M}+\mathrm{H}]^{+} \mathrm{m} / \mathrm{z}\right.$ 772.621 and $\mathrm{PC}(\mathrm{P}-40: 4)[\mathrm{M}+\mathrm{H}]^{+} \mathrm{m} / z$ 822.637), and $\mathrm{TG}(50: 2)[\mathrm{M}+\mathrm{K}]^{+} \mathrm{m} / \mathrm{z} 869.699$ are shown as examples in Figure 4. On-tissue CID experiments (Supplementary Figure 3) confirmed the annotations of $\mathrm{SM}(\mathrm{d} 34: 1)[\mathrm{M}+\mathrm{K}]^{+}, \mathrm{SM}(\mathrm{d} 42: 2)[\mathrm{M}+\mathrm{H}]^{+}, \mathrm{SM}(\mathrm{d} 36: 1)[\mathrm{M}+\mathrm{Na}]^{+}$, and $\mathrm{PC}(\mathrm{P}-$ 40:4) $[\mathrm{M}+\mathrm{H}]^{+}$. While $\mathrm{SM}(\mathrm{d} 42: 2)$ and $\mathrm{SM}(\mathrm{d} 36: 1)$ were moderately detected from the caput to cauda, $\operatorname{SM}(\mathrm{d} 34: 1)$ and $\operatorname{SM}(\mathrm{d} 42: 0)$ were strongly detected in the connective tissue and the sperm accumulated in the cauda (segments 16 to 19$)$, respectively. $\mathrm{PC}(\mathrm{P}-36: 1)$ and $\mathrm{PC}(\mathrm{P}-$ 40:4) were both strongly detected in the cauda but with different localizations. PC(P-36:1) showed a very fine distribution in the smooth muscle of segments 18 and 19, whereas PC(P40:4) appeared to be specific to the stored sperm. Almost all annotated TGs presented the same distribution than TG(50:2) with a strong signal detected in segments 8 to 12 of the caput and corpus. Since TGs are specifically hydrolysed by adipose triglyceride lipase to form diacylglycerols (DGs) we were interested in the localization of DGs. As exemplified by $\operatorname{DG}(34: 2)[\mathrm{M}+\mathrm{K}]^{+} \mathrm{m} / z 631.469$ (Figure 4), all annotated DGs presented the same localization than $\mathrm{TG}(50: 2)$. However, it is important to note that DG can be prompt breakdown products of TG. In this case, the mass difference between a TG fragment ion and a true DG is $3 \mathrm{mDa}$. Distribution analogies have thus to be made with caution.

Although experiments performed in negative ion mode led to a small number of annotations, they allowed the detection of PIs, LysoPEs and seminolipids. All PIs and LysoPEs detected in the negative ion mode presented very fine localizations around or at the edge of the epididymal duct in the different segments as illustrated by $\mathrm{PI}(16: 0)[\mathrm{M}-\mathrm{H}]^{-} \mathrm{m} / \mathrm{z}, 571.289$, $\mathrm{PI}(36: 0)[\mathrm{M}-\mathrm{H}]^{-} \mathrm{m} / \mathrm{z}$ 865.580, and LysoPE(18:0) $[\mathrm{M}-\mathrm{H}]^{-} \mathrm{m} / \mathrm{z}$ 480.309. Seminolipids presented the same localization than $\operatorname{SL}(16: 0 / 16: 0)[\mathrm{M}-\mathrm{H}]^{-} \mathrm{m} / z .795 .528$ abundantly detected in the sperm accumulated in segments 2 to 12 but also in the last segments 18 and 19 of the cauda. All images corresponding to annotated ions can be visualized on the Metaspace platform.

Our results are in accordance with a substantial remodeling of lipid composition during the transit of spermatozoa from the caput to the cauda epididymis. The higher number of plasmalogens and sphingolipids observed in the cauda is consistent with the results obtained by Pyttel et al. in sperm collected from the mouse cauda epididymis ${ }^{17}$. Plasmalogens are 
glycerol ether phospholipids in which the fatty acid in the sn-1 position is linked to the glycerol backbone by an alkenyl ether group. Plasmalogens are considered to be very important players in epididymal maturation due to their antioxidative properties ${ }^{39}$. Rejraji et al. ${ }^{19}$ also observed higher amounts of sphingolipids in the mouse cauda epididymis, precisely in the membranes of epididymosomes and spermatozoa. Sphingolipids are highly involved in the capacitation process before the spermatozoa reach the oocyte and undergo the acrosome reaction. Indeed, sphingolipids are known to slow the loss of sterol, which is an early and mandatory step of capacitation in humans ${ }^{42}$. However, contrary to the results obtained by Pyttel et al. on lipid extracts prepared from mouse epididymal sperm, we observed no significant increase in the proportion of LysoPCs in the rat cauda epididymal tissue. Compared to plasmalogens and sphingolipids, the number and intensity of LysoPCs were relatively weak in our study. This could hinder the detection of the increase in the LysoPCs proportion observed by Pyttel et al. ${ }^{17}$. Moreover, differences between rodent species cannot be excluded. In addition, we found that TGs and DGs were co-localized in segments 8 to 12 . Although we did not found data supporting this hypothesis, this could suggest an important activity of adipose triglyceride lipases in this region. Interestingly, Masaki et al. demonstrated that the alteration of TG metabolism, obtained by the deletion of the Atgl gene, affects spermatogenesis and the maturation process of the male gamete ${ }^{43}$. Seminolipids are sulfogalactosylglycerolipids ${ }^{44,45}$ selectively and very abundantly found in the sperm plasma membrane of mammals including humans ${ }^{46,47}$. They are essential for completion of the spermatogenesis, fertilization and sperm-egg interactions ${ }^{47}$. In the mouse testis, Goto-Inoue et al. showed that SL(16:0/16:0) was detected throughout the tubules whereas SL(16:0/14:0) was mainly found in spermatocytes and SL(17:0/16:0) specifically expressed in spermatids and spermatozoa using IMS ${ }^{48}$. LC-MS/MS experiments showed that SL(16:0/16:0) is the major seminolipid in pachytene spermatocytes, round spermatids and spermatozoa collected from caudal epididymis and vas deferens of mice ${ }^{47}$. Ion images we obtained show for the first time the distribution of seminolipids along the epididymal tissue.

\section{$3 D$ reconstruction of the epididymis head by MALDI FT-ICR imaging}

Despite the implementation of real-time data reduction and an increase in the analysis speed of MALDI mass spectrometers, 3D-MALDI IMS studies are still mainly limited to relatively small datasets. However, Jones et al. ${ }^{30}$ recently performed the 3D reconstruction of a mouse 
lung from 40 sections analyzed with a lateral resolution of $120 \mu \mathrm{m}$ on a MALDI-FTICR. Given the lateral resolution required for the study of a complex organ such as an epididymis, the $3 \mathrm{D}$ reconstruction of the entire organ appeared to be a colossal task.

The 3D models reconstructed for $\mathrm{PC}(38: 4)[\mathrm{M}+\mathrm{K}]^{+} \mathrm{m} / z, 848.557$ and $\mathrm{PC}(38: 5)[\mathrm{M}+\mathrm{Na}]^{+} \mathrm{m} / z$ 830.569 in an epididymis head collected from another animal are shown in Figure 5. The 2DMALDI IMS data showed that the localization of $\mathrm{PC}(38: 4)[\mathrm{M}+\mathrm{K}]^{+} \mathrm{m} / \mathrm{z} 848.557$ was limited to segments 1 to 7 (Figure 5A and supplementary data 2). The 3D-model suggests that the distribution of $\mathrm{PC}(38: 4)[\mathrm{M}+\mathrm{K}]^{+} \mathrm{m} / \mathrm{z} 848.557$ is also limited to these segments in the whole volume of the epididymis head. Although $\mathrm{PC}(38: 5)[\mathrm{M}+\mathrm{Na}]^{+} \mathrm{m} / z \quad 830.569$ appeared to be very abundant in segments 3 to 7 from the 2D MALDI IMS data, the 3D-model suggests that $\mathrm{PC}(38: 5)[\mathrm{M}+\mathrm{Na}]^{+} \mathrm{m} / \mathrm{z}, 830.557$ can also be found in similar abundances in segments 8 to 10 in the whole volume of the epididymis head (Figure 5B and supplementary data 3). This 3D reconstruction of the epididymis head shows that the localization of an analyte can vary across the volume of the tissue and provides information that would have been missed from a single section. With the co-registration of $612 \mathrm{D}$-ion images obtained at a lateral resolution of $50 \mu \mathrm{m}$, our 3D-model of the rat epididymis represents a more complex dataset than the 3Dmodel of mouse lung reconstructed by Jones et al ${ }^{30}$.

\section{Conclusions}

We were able to define an entire new segmentation map based on molecular interpretation using new and promising techniques that are already available, i.e., imaging mass spectrometry and computational methods. The pixel-to-pixel reduction approach combined with clear, noiseless, and smooth segmentation maps already appeared to be an ideal technique to delineate complex and detailed histology structures $31,43,44$. These computational methods enabled automatic determination of the discriminative $\mathrm{m} / z$ values that contributed the most to a given region and the proposition of molecular annotations, confirmed by ontissue CID experiments for some. Our study confirms the substantial remodeling of lipid composition during epididymal maturation and the results are highly complementary to those of previous analyses performed on sperm or tissue extracts collected from the epididymis head and tail. It is noteworthy that MALDI imaging experiments can be subjected to a significant technical variability. The introduction of QC samples such as a mimetic tissue model or highly structured tissue in the analysis workflow could be used to validate the sample preparation and the analytical performances of the instrument, especially when 
images must be taken in different days as is the case with 3D experiments. Moreover, ion suppression effects encountered in all MALDI IMS studies can alter qualitatively and quantitatively the real distribution of detected ions. As suggested by Leopold et al., the use of one internal standard for each major lipid class could be a solution to at least partially reduce the impact of ion suppression ${ }^{49}$. Further work is currently ongoing in our laboratory to integrate our high quality in-situ lipid-distribution dataset with quantitative proteomes obtained for the three main epididymal regions, with the aim to identify the key enzymes involved in lipid metabolism within the organ. Indeed, this pioneering work opens new perspectives for elucidating the role of lipid metabolism in sperm maturation during its transit through the epididymis.

\section{Conflict of interest}

The authors declare no conflict of interest.

\section{Data Availability Statement}

Results of the molecular annotations can be publicly visualized in the datasets named UR1_Epididymis_Head_POS, UR1_Epididymis_Tail_POS, UR1_Epididymis_Head_NEG and UR1_Epididymis_Tail_NEG (http://annotate.metaspace2020.eu/\#/about). The data are also publicly available at the MetaboLights repository under accession code MTBLS58.

\section{Acknowledgments}

The work was supported by structural grants from Biogenouest, Infrastructures en Biologie Santé et Agronomie (IBiSA) and Conseil Régional de Bretagne awarded to C.P. We thank Dr Theodore Alexandrov for stimulating discussions and advices concerning the use of METASPACE.

\section{Authors' contributions}

Mélanie Lagarrigue performed 2D experiments, interpreted and formatted the data and wrote the manuscript.

Régis Lavigne prepared cryosections, performed data acquisition and processing, and participated in writing of the manuscript.

Blandine Guével prepared cryosections and performed data acquisition.

Dennis Trede participated in processing 3D data.

Andrew Palmer assisted us in annotating the data in the beginnings of METASPACE. 
Karine Rondel prepared cryosections.

Laetitia Guillot wrote a R script to automatically associate discriminative $\mathrm{m} / \mathrm{z}$ and annotations from metaspace and select the best salt adducts.

Jan H. Kobarg participated in processing and normalizing of the 3D data.

Charles Pineau conceived the original idea and participated in improving the manuscript.

\section{References}

[1] G.A. Cornwall, New insights into epididymal biology and function. Hum. Reprod. Update. 2009, 15, 213.

[2] J.L. Dacheux, F. Dacheux, New insights into epididymal function in relation to sperm maturation. Reproduction. 2014, 147, R27.

[3] R. Jones, Plasma membrane structure and remodelling during sperm maturation in the epididymis. J. Reprod. Fertil. Suppl. 1998, 53, 73.

[4] C. Kirchhoff, I. Pera, P. Derr, C.H. Yeung, T. Cooper, The molecular biology of the sperm surface. Post-testicular membrane remodelling. Adv. Exp. Med. Biol. 1997, 424, 221.

[5] K. Cleland, The structure and function of the Epididymis. 1. The histology of the Rat Epididymis. Australian Journal of Zoology. 1957, 5, 223.

[6] B. Robaire, L. Hermo, Efferent ducts, epididymis, and Vas deferens: structure,

functions, and their regulation, in The Physiology of Reproduction, (Eds: E. Knobil, J. Neil), Raven Press, New York, 1988, pp. 1000-1080.

[7] C. Kirchhoff, Gene expression in the epididymis. Int. Rev. Cytol. 1999, 188, 133.

[8] T.T. Turner, D. Bomgardner, J.P. Jacobs, Q.A. Nguyen, Association of segmentation of the epididymal interstitium with segmented tubule function in rats and mice. Reproduction. 2003, $125,871$.

[9] S.A. Jelinsky, T.T. Turner, H.J. Bang, J.N. Finger, M.K. Solarz, E. Wilson, E.L. Brown, G.S. Kopf, D.S. Johnston, The rat epididymal transcriptome: comparison of segmental gene expression in the rat and mouse epididymides. Biol. Reprod. 2007, 76, 561.

[10] K.M. Jervis, B. Robaire, Dynamic changes in gene expression along the rat epididymis. Biol. Reprod. 2001, 65, 696.

[11] B. Guyonnet, F. Dacheux, J.-L. Dacheux, J.-L. Gatti, The epididymal transcriptome and proteome provide some insights into new epididymal regulations. J. Androl. 2011, 32, 651.

[12] M.G. Gervasi, P.E. Visconti, Molecular changes and signaling events occurring in spermatozoa during epididymal maturation. Andrology. 2017, 5, 204.

[13] H. Yuan, A. Liu, L. Zhang, H. Zhou, Y. Wang, H. Zhang, G. Wang, R. Zeng, Y.

Zhang, Z. Chen, Proteomic profiling of regionalized proteins in rat epididymis indicates consistency between specialized distribution and protein functions. J. Proteome Res. 2006, 5, 299.

[14] S.-G. Hu, A.-J. Liang, G.-X. Yao, X.-Q. Li, M. Zou, J.-W. Liu, Y. Sun, The dynamic metabolomic changes throughout mouse epididymal lumen fluid potentially contribute to sperm maturation. Andrology. 2018, 6, 247. 
[15] N. Kim, H. Nakamura, H. Masaki, K. Kumasawa, K.-I. Hirano, T. Kimura, Effect of lipid metabolism on male fertility. Biochem. Biophys. Res. Commun. 2017, 485, 686.

[16] G. Haidl, C. Opper, Changes in lipids and membrane anisotropy in human spermatozoa during epididymal maturation. Hum. Reprod. 1997, 12, 2720.

[17] S. Pyttel, A. Nimptsch, J. Böttger, K. Zschörnig, U. Jakop, J. Wegener, K. Müller, U. Paasch, J. Schiller, Changes of murine sperm phospholipid composition during epididymal maturation determined by MALDI-TOF mass spectrometry. Theriogenology. 2014, 82, 396. [18] H. Sato, Y. Taketomi, Y. Isogai, Y. Miki, K. Yamamoto, S. Masuda, T. Hosono, S. Arata, Y. Ishikawa, T. Ishii, T. Kobayashi, H. Nakanishi, K. Ikeda, R. Taguchi, S. Hara, I. Kudo, M. Murakami, Group III secreted phospholipase A2 regulates epididymal sperm maturation and fertility in mice. J. Clin. Invest. 2010, 120, 1400.

[19] H. Rejraji, B. Sion, G. Prensier, M. Carreras, C. Motta, J.-M. Frenoux, E. Vericel, G. Grizard, P. Vernet, J.R. Drevet, Lipid remodeling of murine epididymosomes and spermatozoa during epididymal maturation. Biol. Reprod. 2006, 74, 1104.

[20] M. Lagarrigue, R. Lavigne, B. Guevel, E. Com, P. Chaurand, C. Pineau, MatrixAssisted Laser Desorption/Ionization Imaging Mass Spectrometry: A Promising Technique for Reproductive Research. Biology of Reproduction. 2012, 86,.

[21] P. Chaurand, S. Fouchecourt, B.B. DaGue, B.J. Xu, M.L. Reyzer, M.C. OrgebinCrist, R.M. Caprioli, Profiling and imaging proteins in the mouse epididymis by imaging mass spectrometry. Proteomics. 2003, 3, 2221.

[22] D.J. Ryan, D. Nei, B.M. Prentice, K.L. Rose, R.M. Caprioli, J.M. Spraggins, Protein identification in imaging mass spectrometry through spatially targeted liquid microextractions. Rapid Commun. Mass Spectrom. 2018, 32, 442.

[23] A.C. Crecelius, U.S. Schubert, F. von Eggeling, MALDI mass spectrometric imaging meets "omics": recent advances in the fruitful marriage. Analyst. 2015, 140, 5806.

[24] A. Palmer, P. Phapale, I. Chernyavsky, R. Lavigne, D. Fay, A. Tarasov, V. Kovalev, J. Fuchser, S. Nikolenko, C. Pineau, M. Becker, T. Alexandrov, FDR-controlled metabolite annotation for high-resolution imaging mass spectrometry. Nat. Methods. 2017, 14, 57.

[25] A.C. Crecelius, D.S. Cornett, R.M. Caprioli, B. Williams, B.M. Dawant, B.

Bodenheimer, Three-dimensional visualization of protein expression in mouse brain structures using imaging mass spectrometry. J. Am. Soc. Mass. Spectrom. 2005, 16, 1093.

[26] M. Andersson, M.R. Groseclose, A.Y. Deutch, R.M. Caprioli, Imaging mass spectrometry of proteins and peptides: 3D volume reconstruction. Nature Methods. 2008, 5, 101.

[27] E.H. Seeley, R.M. Caprioli, 3D imaging by mass spectrometry: a new frontier. Anal. Chem. 2012, 84, 2105.

[28] A.D. Palmer, T. Alexandrov, Serial 3D imaging mass spectrometry at its tipping point. Anal. Chem. 2015, 87, 4055.

[29] J. Oetjen, K. Veselkov, J. Watrous, J.S. McKenzie, M. Becker, L. Hauberg-Lotte, J.H. Kobarg, N. Strittmatter, A.K. Mróz, F. Hoffmann, D. Trede, A. Palmer, S. Schiffler, K. Steinhorst, M. Aichler, R. Goldin, O. Guntinas-Lichius, F. von Eggeling, H. Thiele, K. Maedler, A. Walch, P. Maass, P.C. Dorrestein, Z. Takats, T. Alexandrov, Benchmark datasets for 3D MALDI- and DESI-imaging mass spectrometry. Gigascience. 2015, 4, 20.

[30] E.E. Jones, C. Quiason, S. Dale, S.K. Shahidi-Latham, Feasibility Assessment of a 
MALDI FTICR Imaging Approach for the 3D Reconstruction of a Mouse Lung. J. Am. Soc. Mass Spectrom. 2017, 28, 1709.

[31] T. Alexandrov, J.H. Kobarg, Efficient spatial segmentation of large imaging mass spectrometry datasets with spatially aware clustering. Bioinformatics. 2011, 27, i230.

[32] O. Klein, K. Strohschein, G. Nebrich, J. Oetjen, D. Trede, H. Thiele, T. Alexandrov, P. Giavalisco, G.N. Duda, P. von Roth, S. Geissler, J. Klose, T. Winkler, MALDI imaging mass spectrometry: discrimination of pathophysiological regions in traumatized skeletal muscle by characteristic peptide signatures. Proteomics. 2014, 14, 2249.

[33] S.O. Deininger, M.P. Ebert, A. Futterer, M. Gerhard, C. Rocken, MALDI Imaging Combined with Hierarchical Clustering as a New Tool for the Interpretation of Complex Human Cancers. J. Proteome Res. 2008,

[34] D. Trede, S. Schiffler, M. Becker, S. Wirtz, K. Steinhorst, J. Strehlow, M. Aichler, J.H. Kobarg, J. Oetjen, A. Dyatlov, S. Heldmann, A. Walch, H. Thiele, P. Maass, T.

Alexandrov, Exploring three-dimensional matrix-assisted laser desorption/ionization imaging mass spectrometry data: three-dimensional spatial segmentation of mouse kidney. Anal.

Chem. 2012, 84, 6079.

[35] S. Rauser, C. Marquardt, B. Balluff, S.O. Deininger, C. Albers, E. Belau, R. Hartmer, D. Suckau, K. Specht, M.P. Ebert, M. Schmitt, M. Aubele, H. Hofler, A. Walch,

Classification of HER2 receptor status in breast cancer tissues by MALDI imaging mass spectrometry. J. Proteome Res. 2010, 9, 1854.

[36] J.M. Lotz, F. Hoffmann, J. Lotz, S. Heldmann, D. Trede, J. Oetjen, M. Becker, G.

Ernst, P. Maas, T. Alexandrov, O. Guntinas-Lichius, H. Thiele, F. von Eggeling, Integration of 3D multimodal imaging data of a head and neck cancer and advanced feature recognition.

Biochim Biophys Acta Proteins Proteom. 2017, 1865, 946.

[37] D.S. Cornett, M.L. Reyzer, P. Chaurand, R.M. Caprioli, MALDI imaging mass spectrometry: molecular snapshots of biochemical systems. Nat. Methods. 2007, 4, 828. [38] W. De Grava Kempinas, G.R. Klinefelter, Interpreting histopathology in the epididymis. Spermatogenesis. 2014, 4, e979114.

[39] B. Fuchs, U. Jakop, F. Göritz, R. Hermes, T. Hildebrandt, J. Schiller, K. Müller, MALDI-TOF "fingerprint" phospholipid mass spectra allow the differentiation between ruminantia and feloideae spermatozoa. Theriogenology. 2009, 71, 568.

[40] J.V. Busik, G.E. Reid, T.A. Lydic, Global analysis of retina lipids by complementary precursor ion and neutral loss mode tandem mass spectrometry. Methods Mol. Biol. 2009, 579,33 .

[41] B. Fuchs, K. Muller, U. Paasch, J. Schiller, Lysophospholipids: potential markers of diseases and infertility? Mini Rev Med Chem. 2012, 12, 74.

[42] N.L. Cross, Sphingomyelin modulates capacitation of human sperm in vitro. Biol. Reprod. 2000, 63, 1129.

[43] H. Masaki, N. Kim, H. Nakamura, K. Kumasawa, E. Kamata, K.-I. Hirano, T. Kimura, Long-chain fatty acid triglyceride (TG) metabolism disorder impairs male fertility: a study using adipose triglyceride lipase deficient mice. Mol. Hum. Reprod. 2017, 23, 452.

[44] J.G. Alvarez, B.T. Storey, M.L. Hemling, R.L. Grob, High-resolution proton nuclear magnetic resonance characterization of seminolipid from bovine spermatozoa. J. Lipid Res.

1990, 31, 1073. 
[45] M. Attar, M. Kates, M. Bou Khalil, D. Carrier, P.T. Wong, N. Tanphaichitr, A Fourier-transform infrared study of the interaction between germ-cell specific sulfogalactosylglycerolipid and dimyristoylglycerophosphocholine. Chem. Phys. Lipids. 2000, 106, 101.

[46] P. Lopalco, R. Vitale, Y.S. Cho, P. Totaro, A. Corcelli, S. Lobasso, Alteration of Cholesterol Sulfate/Seminolipid Ratio in Semen Lipid Profile of Men With

Oligoasthenozoospermia. Front. Physiol. 2019, 10, 1344.

[47] N. Tanphaichitr, K. Kongmanas, K.F. Faull, J. Whitelegge, F. Compostella, N. GotoInoue, J.-J. Linton, B. Doyle, R. Oko, H. Xu, L. Panza, A. Saewu, Properties, metabolism and roles of sulfogalactosylglycerolipid in male reproduction. Progress in Lipid Research. 2018, 72,18 .

[48] N. Goto-Inoue, T. Hayasaka, N. Zaima, M. Setou, The specific localization of seminolipid molecular species on mouse testis during testicular maturation revealed by imaging mass spectrometry. Glycobiology. 2009, 19, 950.

[49] J. Leopold, Y. Popkova, K.M. Engel, J. Schiller, Recent Developments of Useful MALDI Matrices for the Mass Spectrometric Characterization of Lipids. Biomolecules. 2018, 8,173 .

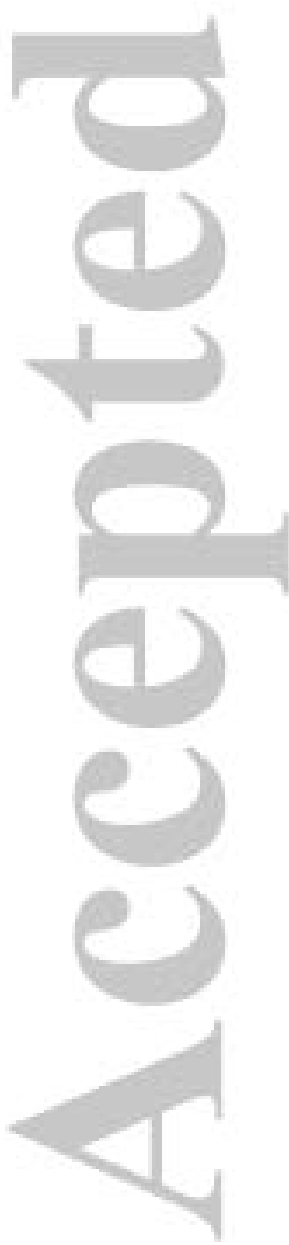


Table 1. The 19 intra-regional segments determined from histological observation are composed of several molecular clusters obtained from spatial segmentation in positive and in negative ion modes.

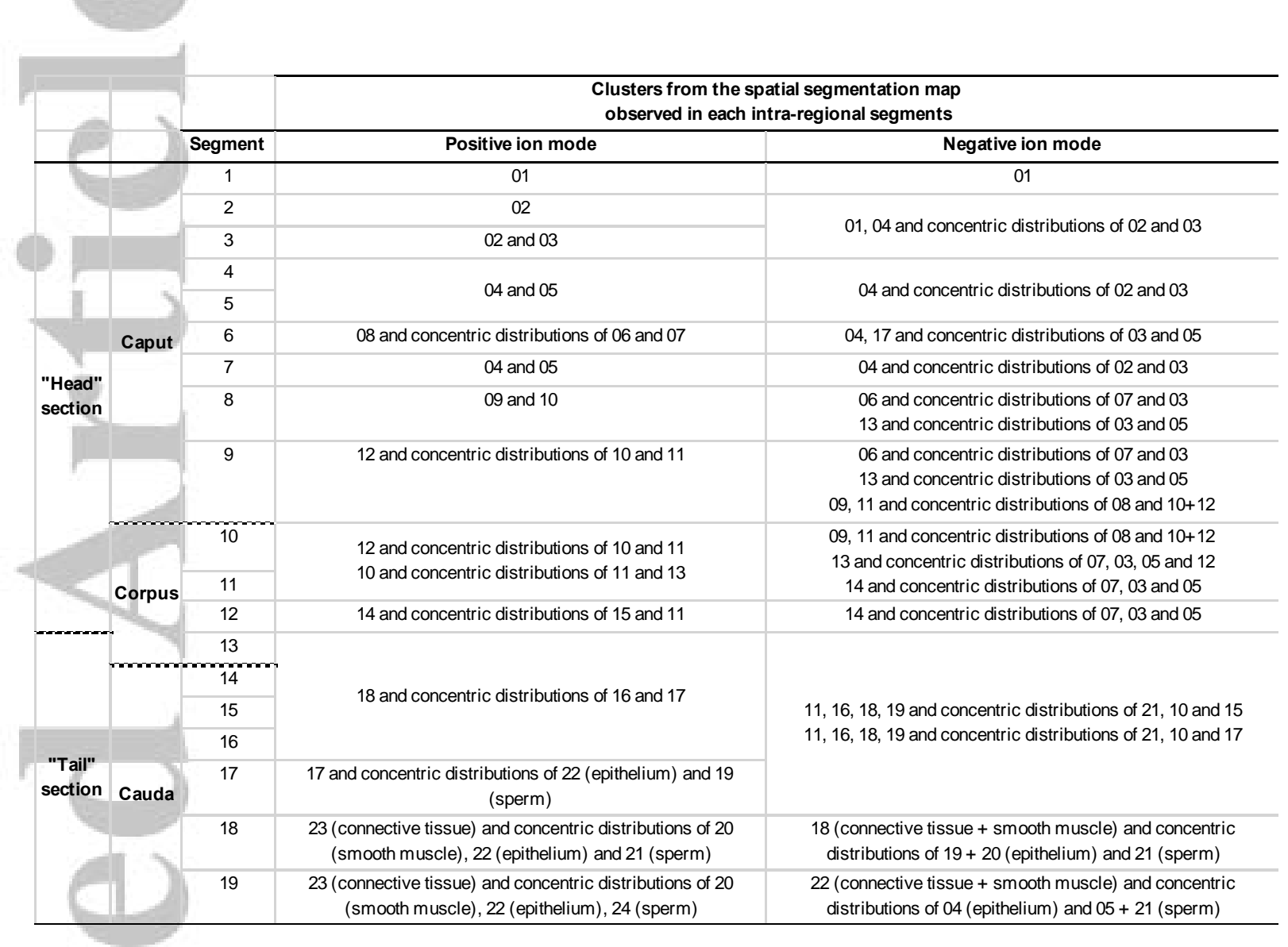


Figure 1

A) Optical image

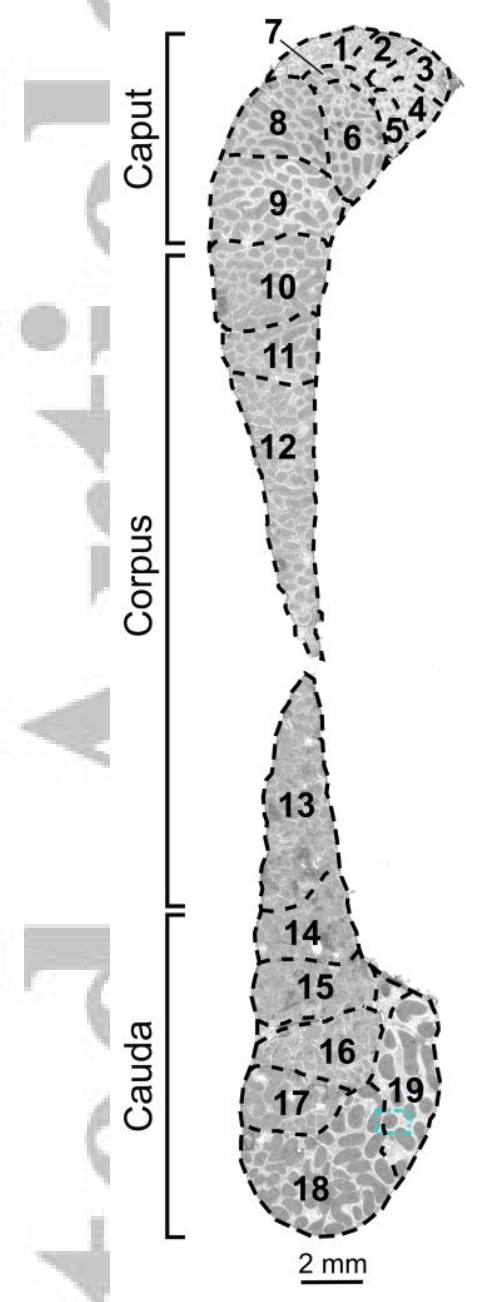

D) epithelium

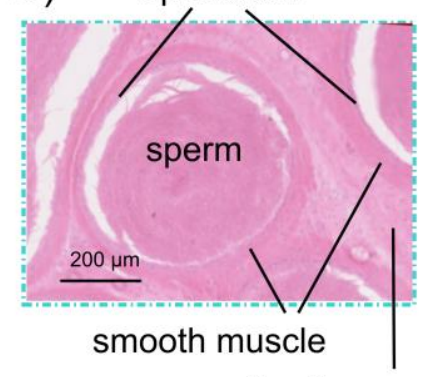

connective tissue
B) Positive ion mode

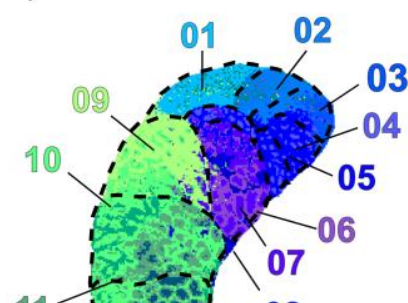

08
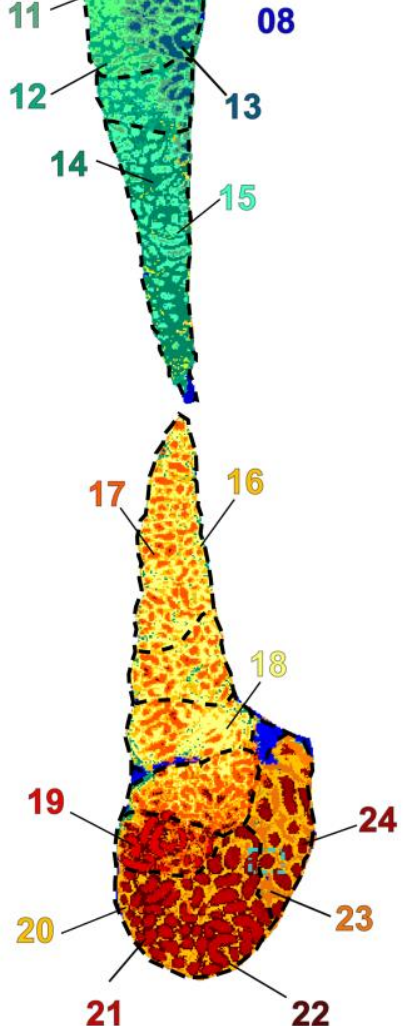

E)

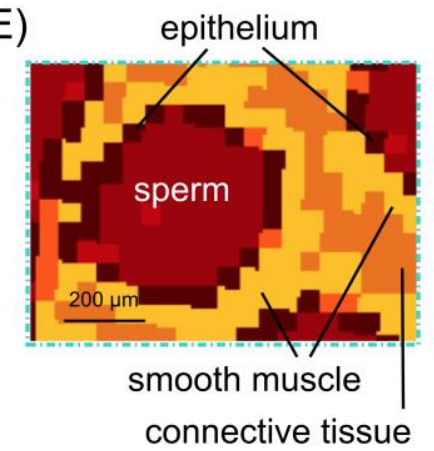

C) Negative ion mode

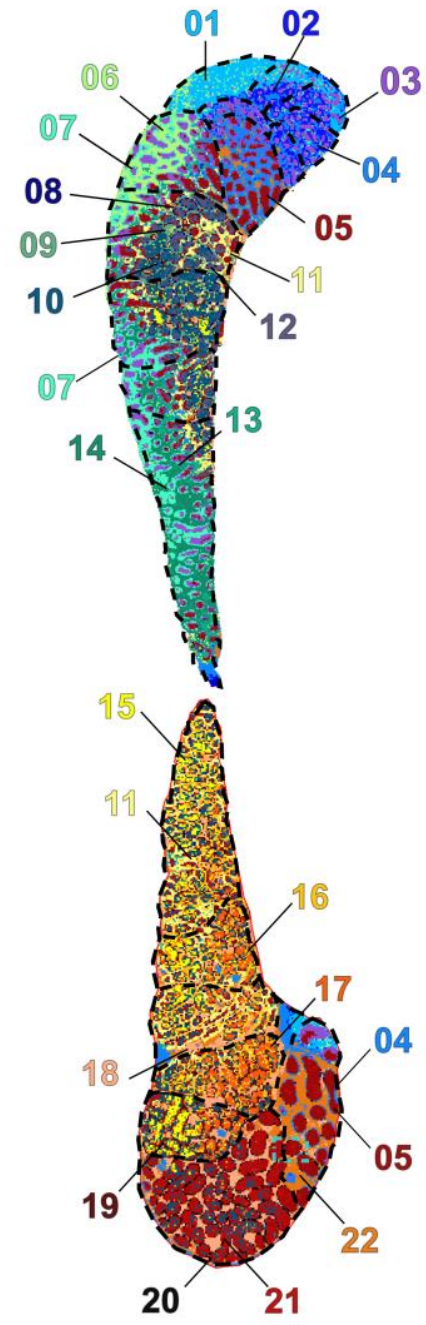

F)

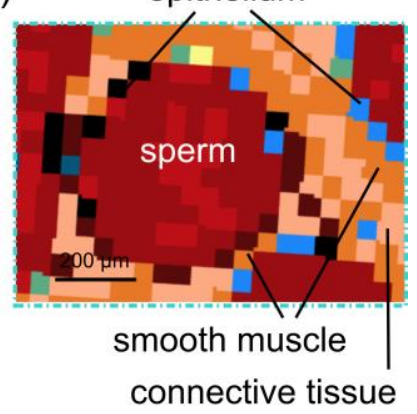

Figure 1. Different segmentation of the rat epididymis is observed at the histological and molecular levels. A) The 19 intra-regional segments described by Jelinsky et al. ${ }^{9}$ are represented in the optical images of "head" and "tail" sections analyzed by MALDI IMS. B) The spatial segmentation maps obtained at the molecular level are composed of B) 24 clusters in the positive ion mode and C) 22 clusters in the negative ion mode. Magnifications of the areas located in the blue frames from D) a consecutive section stained with $H \& E$, and from the spatial segmentation maps obtained $\mathrm{E}$ ) in positive and F) in negative ion modes. 


\section{Figure 2}
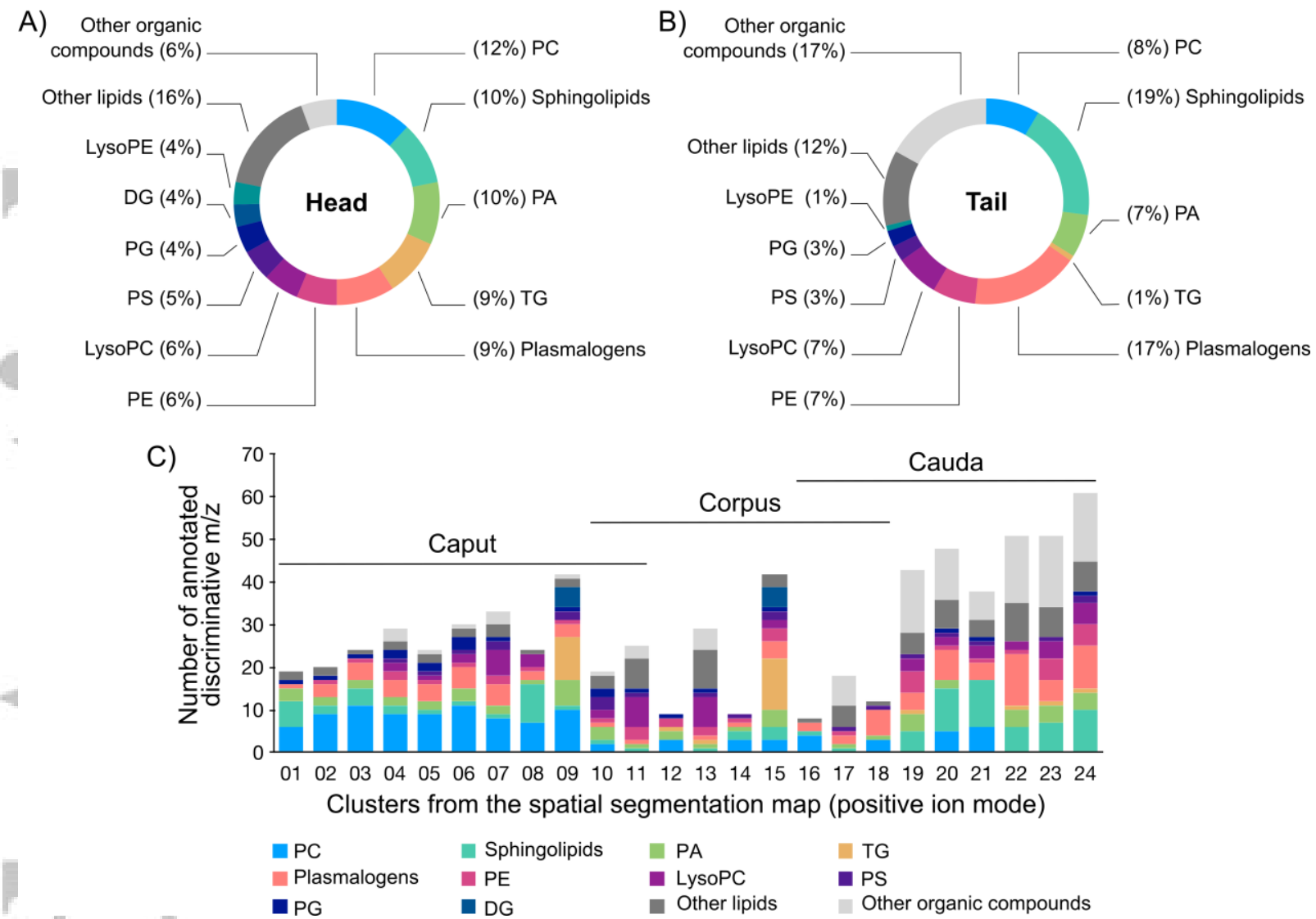

Figure 2. The lipid composition of the epididymis differs substantially from head to tail. Annotations of discriminative $\mathrm{m} / \mathrm{z}$ values obtained in positive and negative ion modes for the epididymis A) head and B) tail. C) Annotations of discriminative $\mathrm{m} / \mathrm{z}$ values obtained for each cluster of the spatial segmentation map in positive ion mode. For each cluster, adducts of the same species were considered to be duplicates.

Abbreviations: PC: phosphatidylcholines, PA: glycerophosphate, TG: triacylgycerol, PE: phosphatidylethanolamines, LysoPC: lysophosphatidylcholine, PS: phosphatidylserine, PG: phosphatidylglycerol, DG: diacylglycerol, LysoPE: lysophosphatidylethanolamine. 


\section{Figure 3}
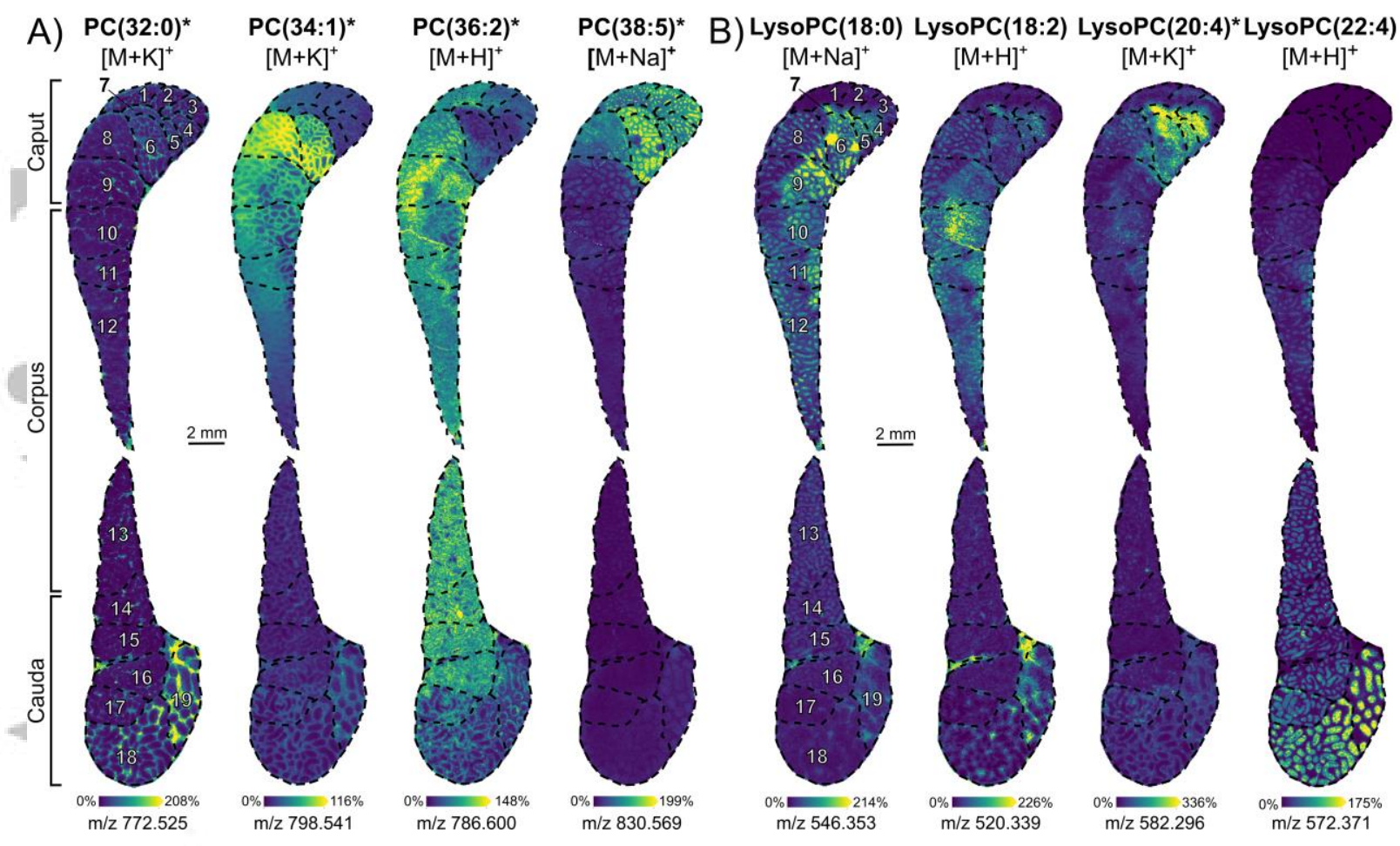

Figure 3. MALDI IMS reveals the in-situ localization of several PCs and LysoPCs. Ion images of A) $\mathrm{PC}(32: 0)[\mathrm{M}+\mathrm{K}]^{+} m / z$ 772.525, $\mathrm{PC}(34: 1)[\mathrm{M}+\mathrm{K}]^{+} m / z$ 798.541, $\mathrm{PC}(36: 2)$ $[\mathrm{M}+\mathrm{H}]^{+} \mathrm{m} / z$ 786.600 and PC(38:5) $[\mathrm{M}+\mathrm{Na}]^{+} \mathrm{m} / z$ 830.569 and B) LysoPC(18:0) $[\mathrm{M}+\mathrm{Na}]^{+} \mathrm{m} / \mathrm{z}$ 546.353, LysoPC(18:2) $[\mathrm{M}+\mathrm{H}]^{+} \mathrm{m} / z$ 520.339, LysoPC(20:4) $[\mathrm{M}+\mathrm{K}]^{+} \mathrm{m} / z 582.296$ and LysoPC(22:4) $[\mathrm{M}+\mathrm{H}]^{+} \mathrm{m} / z$ 572.371. Ions for which the annotation was confirmed by ontissue CID (Supplementary Figure 3) are marked with an asterisk. Numbers indicated on the ion images correspond to the 19 intra-regional segments. Ion images are presented in veridis color scale automatically adjusted with the hot spot removal option. 
Figure 4

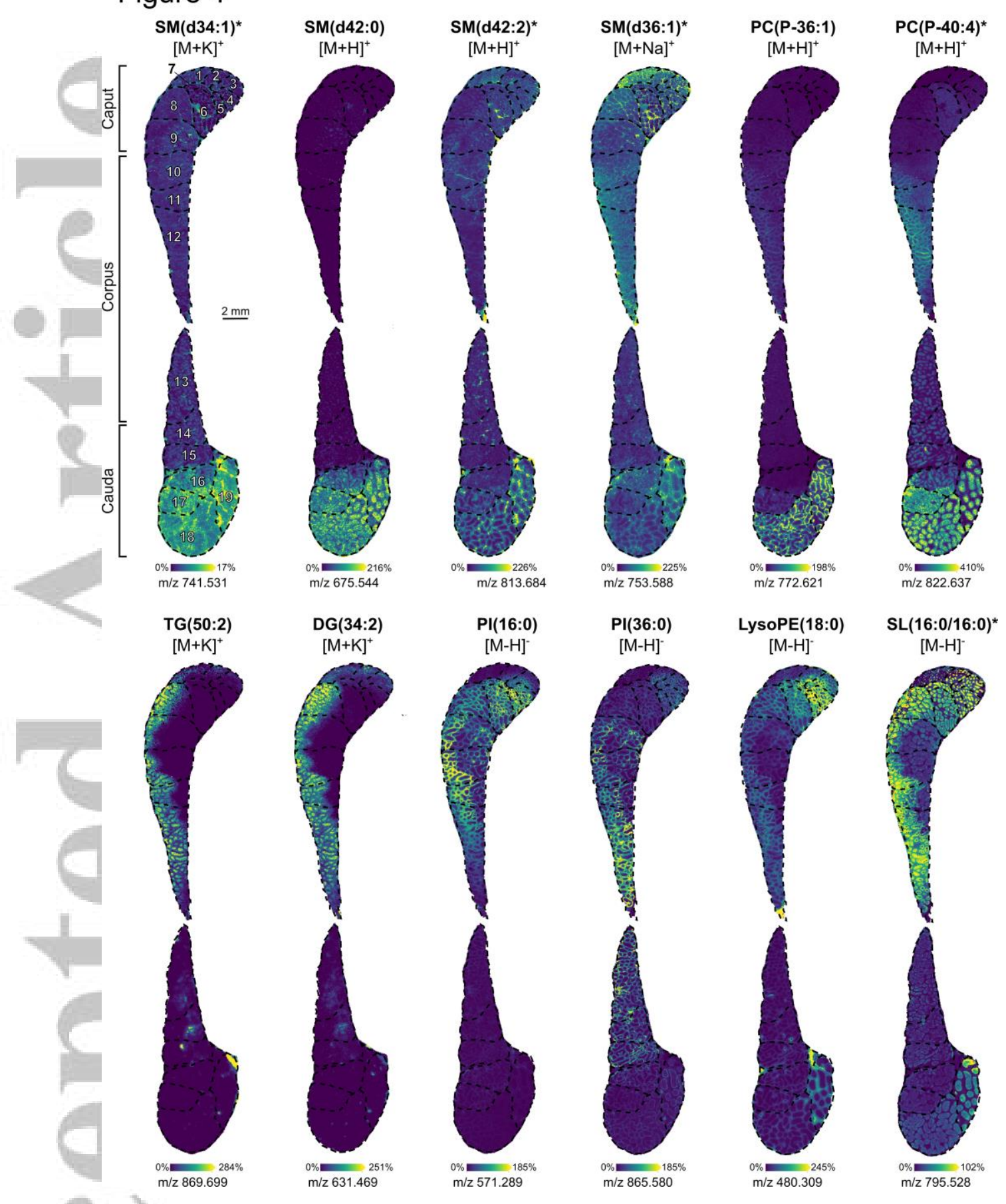

Figure 4. MALDI IMS reveals the in-situ localization of several lipid classes. Ion images of $\mathrm{SM}(\mathrm{d} 34: 1)[\mathrm{M}+\mathrm{K}]^{+} m / z$ 741.531, $\mathrm{SM}(\mathrm{d} 42: 0)[\mathrm{M}+\mathrm{H}]^{+} \mathrm{m} / z$ 675.544, $\mathrm{SM}(\mathrm{d} 42: 2)[\mathrm{M}+\mathrm{H}]^{+} \mathrm{m} / z$ 813.684, and $\mathrm{SM}(\mathrm{d} 36: 1)[\mathrm{M}+\mathrm{Na}]^{+} \mathrm{m} / z$ 753.588; plasmalogens $\mathrm{PC}(\mathrm{P}-36: 1)[\mathrm{M}+\mathrm{H}]^{+} \mathrm{m} / \mathrm{z}$ 772.621 and $\mathrm{PC}(\mathrm{P}-40: 4)[\mathrm{M}+\mathrm{H}]^{+} \mathrm{m} / z$ 822.637; TG(50:2) $[\mathrm{M}+\mathrm{K}]^{+} \mathrm{m} / z$ 869.699, DG(34:2)

$[\mathrm{M}+\mathrm{K}]^{+} m / z$ 631.469, $\mathrm{PI}(16: 0)[\mathrm{M}-\mathrm{H}]^{-} \mathrm{m} / z$ 571.289, $\mathrm{PI}(36: 0)[\mathrm{M}-\mathrm{H}]^{-} \mathrm{m} / z$ 865.580,

LysoPE(18:0) $[\mathrm{M}-\mathrm{H}]^{-} \mathrm{m} / \mathrm{z}$ 480.309, and SL(16:0/16:0) $[\mathrm{M}-\mathrm{H}]^{-} \mathrm{m} / z$ 795.528. Ions for which the annotation was confirmed by on-tissue CID (Supplementary Figure 3) are marked with an asterisk. Numbers indicated on the first ion image correspond to the 19 intra-regional segments. Ion images are presented in veridis color scale automatically adjusted with the hot spot removal option. 


\section{Figure 5}

\section{A) $\mathrm{PC}(38: 4)^{*}[\mathrm{M}+\mathrm{K}]^{+} \mathrm{m} / \mathrm{z} 848.557$}
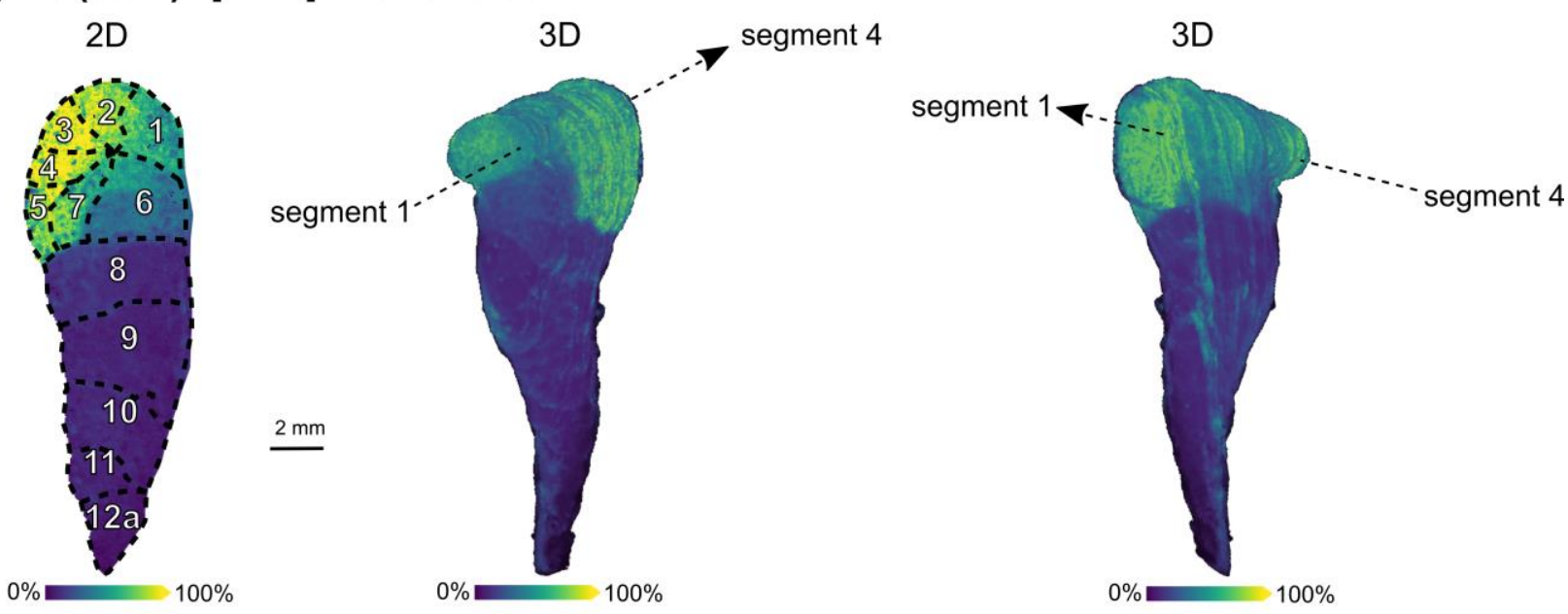

B) $\mathrm{PC}(38: 5)^{*}[\mathrm{M}+\mathrm{Na}]^{+} \mathrm{m} / \mathrm{z} 830.569$
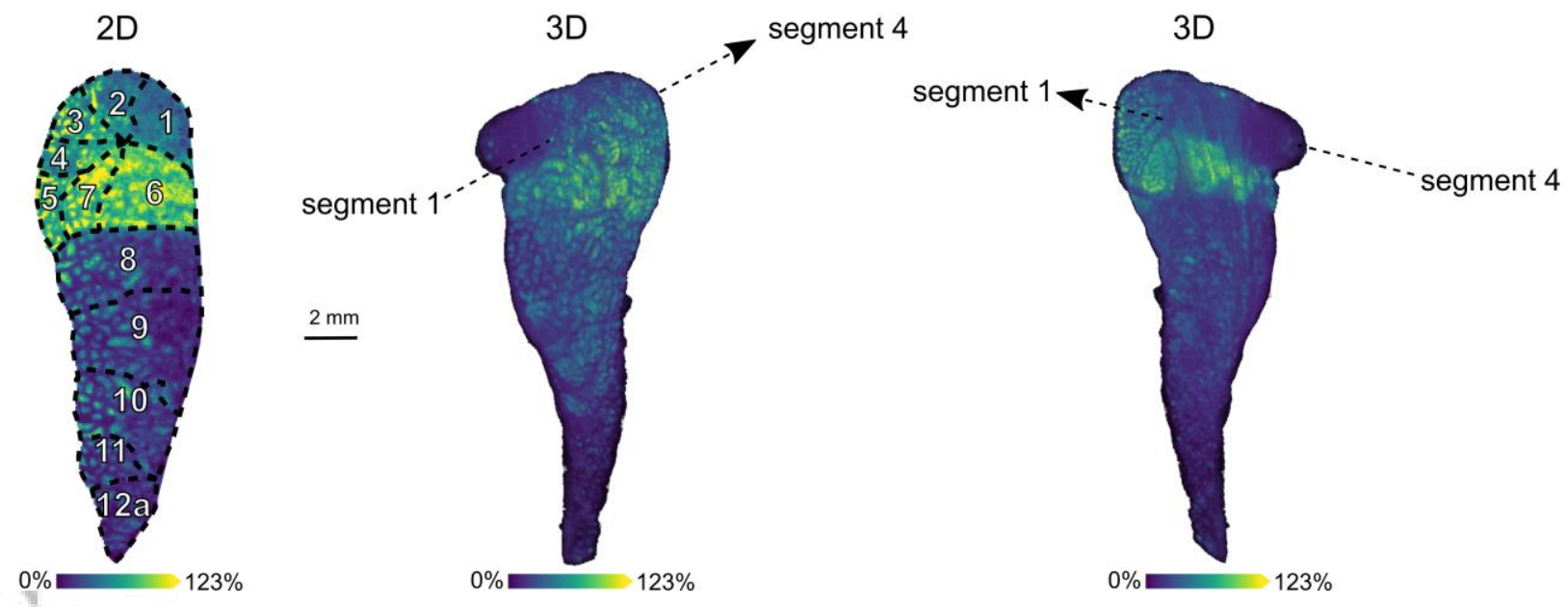

Figure 5. 3D-MALDI IMS models reconstructed for $\mathrm{PC}(38: 4)[\mathrm{M}+\mathrm{K}]^{+} \mathrm{m} / \mathrm{z} 848.557$ and $\mathrm{PC}(38: 5)[\mathrm{M}+\mathrm{Na}]^{+} \mathrm{m} / z 830.569$ in the epididymis head. The asterisk indicates that the annotation was confirmed by on-tissue CID (Supplementary Figure 3). Numbers indicated on the ion image correspond to the intra-regional segments of the epididymis head. 